\title{
Research engagement of health sciences librarians: a survey of research-related activities and attitudes EC
}

\author{
Susan Lessick, MA, MLS, AHIP, FMLA; Carol Perryman, PhD; Brooke L. Billman, MA, AHIP; Kristine M. Alpi, \\ MLS, MPH, AHIP; Sandra L. De Groote, MLIS, AHIP; Ted D. Babin Jr.
}

See end of article for authors' affiliations.

DOI: http://dx.doi.org/10.3163/1536-5050.104.2.015

\begin{abstract}
Introduction: The extent to which health sciences librarians are engaged in research is a little-studied question. This study assesses the research activities and attitudes of Medical Library Association (MLA) members, including the influence of work affiliation.

Methods: An online survey was designed using a combination of multiple-choice and open-ended questions and distributed to MLA members. Responses were analyzed using descriptive statistics, content analysis, and significance testing. The authors used statistical tools and categorized openended question topics by the constant comparative method, also applying the broad subject categories used in a prior study. Pearson's chi-square analysis was performed on responses to determine significant differences among respondents employed in three different institutional
\end{abstract} environments.

Results: Analysis showed that $79 \%$ of respondents read research articles at least once a month; $58 \%$ applied published research studies to practice; $44 \%$ had conducted research; $62 \%$ reported acting on research had enhanced their libraries; 38\% had presented findings; and 34\% had authored research articles. Hospital librarians were significantly less likely than academic librarians to have participated in research activities. Highly ranked research benefits, barriers, and competencies of health sciences librarians are described.

Conclusions: Findings indicate that health sciences librarians are actively engaged in research activities. Practice implications for practitioners, publishers, and stakeholders are discussed. Results suggest that practitioners can use published research results and results from their own research to affect practice decisions and improve services. Future studies are needed to confirm and extend these findings, including the need for intervention studies to increase research and writing productivity.

Keywords: Libraries, Medical; Library Surveys; Research Report; Library Science Research

Health information research is essential for health sciences librarians to create new knowledge and advance evidence-based practice. The Medical Library Association (MLA), with more than 3,700 health sciences information professional members, has long recognized the importance and benefits of research in health sciences information practice through research policies [1-3], peer-reviewed publications, and funding and recognition of

A supplemental appendix and supplemental Tables 1-19 are available with the online version of this journal. research projects. Studies on the extent to which health sciences librarians are engaged in research are outdated or limited in scope, having been conducted prior to developments in evidence-based librarianship (EBL) [4], the emergence of the informationist role of the health sciences librarian [5, 6], and MLA research initiatives, such as the 2007 Research Imperative: The Research Policy Statement of the Medial Library Association [3] and research agenda [7].

The goal of this study is to gain a more comprehensive understanding of the research 
activities and attitudes of health sciences librarians. The research questions are:

- To what extent do health sciences librarians read library research literature and apply the results of published research to their practice?

- Do they conduct their own research or participate in research grants, and if so, how and what do they study and does the use of research improve their libraries?

- Where and how do they share their findings?

- Are their research activities and attitudes affected by work affiliation?

- What do they perceive as their research skill levels and the benefits, limiting factors, and potential of collaborative opportunities and additional training to increasing their participation in research?

\section{METHODOLOGY}

In February 2011, the MLA Research Section conducted an online survey using SurveyMonkey to assess the research activities and attitudes of MLA members as part of a broader planning process that informed the MLA Research Section Vision Statement and Strategic Plan 2012-21016 [8]. A ninemember planning team developed and pilot-tested the survey instrument, consisting of thirty-five closed- and open-ended questions with integrated skip logic (Appendix A, online only). The survey was announced via MLA-FOCUS to all MLA members and available online between February 1 and February 25, 2011. Two reminders were sent during this period.

The survey was reviewed and determined to be exempt from human subject review by the Institutional Review Board at the University of Illinois at Chicago on July 24, 2012. Internet protocol (IP) and email addresses were stripped before the data were analyzed. Analysis for closedended questions included descriptive statistics and significance testing across subgroups based on institutional affiliation, educational level, and years since obtaining a master's degree in library science. Using SPSS, the team performed Pearson's chisquare analysis with significance threshold set at $p \leq 0.05$ for each closed-ended question by institutional affiliation: academic medical library, hospital library, and "other." For each open-ended question, two authors independently coded the responses using the constant comparative method [9], and discrepancies were resolved through discussion. Five broad subject categories were also applied [10, 11]. Online only Table 1 outlines the subject classification scheme with broad and specific subject categories and definitions.

\section{RESULTS}

\section{Demographic and institutional information}

Based on the MLA membership at the time of the survey [12], the survey response rate was $17 \%$ with a $\pm 3.58 \%$ margin of error $(95 \%$ confidence interval). Academic library respondents represented almost half of all respondents (49\%), while hospital library respondents represented more than one-third (37\%). Most of the respondents (61\%) had received their master's degree in library science more than 10 years ago, and the vast majority of respondents had earned a master's degree in library or information science $(90 \%)$. In contrast, far fewer had earned a master's degree in a subject area other than library or information science $(21 \%)$, and even fewer respondents had doctoral degrees (5\%) (Table 2, online only).

This response rate is consistent with the response rates of the 2007 MLA Membership Survey [13] and the 2012 MLA Compensation and Benefits Survey [14]. Both MLA surveys reflected a similar proportionate distribution between academic (both $44 \%$ ) and hospital librarian respondents (both 37\%). Like our study, a large majority of respondents in the MLA surveys had been in the field more than 10 years $(61 \%$ and $74 \%$, respectively). The MLA studies also showed similar high percentages of respondents who had obtained master degrees in library science $(90 \%$ and $86 \%$, respectively) and low percentages of respondents with doctoral degrees (both 5\%). However, a higher percentage of respondents who had master degrees in additional subject areas was noted in our survey $(21 \%$ versus $4 \%$ in the 2007 MLA survey).

\section{Reading and application of published research}

Almost all respondents reported frequencies of research and non-research reading $(97 \%)$, and onethird reported reading research literature once per month. A statistically significant difference was found between groups concerning the frequency of reading research publications: a greater percentage of academic librarians ( $88 \%$ ) read research literature at least once a month compared to hospital librarians $(68 \%)$ (Table 3, online only). 
More than half of respondents (58\%) had applied published research studies to practice. Significantly more academic librarians reported that they had applied research to practice $(70 \%)$ compared to hospital librarians (43\%) (Table 4, online only). A high percentage of respondents who used research in practice $(89 \%)$ provided examples of specific practice applications of research findings, which were classified by subject and are listed in online only Table 5. Findings showed that half of the published research that had been consulted to support practice fell into the broad categories of either end-user education $(27 \%)$ or public services $(23 \%)$.

\section{Research activities}

Almost half of the respondents (44\%) had designed and conducted their own research (Table 6, online only). Of those responding, nearly one-fourth (24\%) reported the use of quantitative research methods, with slightly fewer respondents $(18 \%)$ reporting the use of qualitative methods and more than half (54\%) indicating they had used mixed methods (Table 7, online only). Statistically significant differences were observed among groups: over half worked in academic libraries (59\%), while just under one-quarter were (23\%) employed in hospital libraries. Hospital librarians also reported using exclusively qualitative research methods significantly more often than did academic librarians ( $32 \%$ and $15 \%$, respectively). Also of significance was the finding that more than half of the librarians in academic settings reported using mixed methods research (58\%), while fewer hospital librarians used mixed methods (37\%). Applied research topics represented $88 \%$ of the studies reported by respondents. Specific research topics were: public services $(28 \%)$, information behavior and use research (21\%), and collectionrelated research (14\%). The list of topics and subtopics are shown in online only Table 8 .

Over half of the respondents had acted on research to improve or initiate new library collections, services, or operations $(62 \%)$, whereas no significant difference was noted between groups (Table 9, online only). Most examples of changes that respondents provided fell into the categories of enduser education (23\%), public services $(21 \%)$, and collection management (14\%) (Table 10, online only). Most often respondents reported that existing services were modified (69\%); over one-quarter instituted new services (28\%); and only a few reported using research evidence to cease activities.

\section{Grant activities}

Survey findings showed that one-third of the respondents indicated they had written or participated in writing research grant proposals: a large majority (82\%) had at least 1 proposal funded, while $17 \%$ received funding for 5 or more proposals. A significant difference was noted between groups, with academic librarians (65\%) reporting almost 3 times more grant participation than hospital librarians (22\%) (Table 11, online only). The 5 major sources of funding were the National Network of Libraries of Medicine (26\%), the National Library of Medicine (17\%), MLA (10\%), internal institutional support $(9 \%)$, and the Institute of Museum and Library Services (5\%) (Table 12, online only).

Applied topics accounted for $81 \%$ of the research grants described; however, $14 \%$ did not directly relate to libraries but to health research. A breakdown by topic indicated the 3 most common grant subject areas were outreach to underserved populations, patient and consumers, and training for health care professionals (Table 13, online only).

\section{Presentation and publishing of research}

Results indicated that $38 \%$ of respondents had presented research findings at a professional meeting and that one-third had authored or coauthored a research article (34\%), many of them authoring more than 1 article (Table 14, online only). Compared to hospital librarians, a significantly higher number of academic librarians reported presentation activities (72\% versus $15 \%)$. Significantly more academic librarians reported they had published at least 1 article than did hospital librarians (72\% versus $16 \%$ ). Additionally, the survey showed that respondents published in a broad range of journals with the Journal of the Medical Library Association (JMLA) ranking the highest (25\%) and Medical Reference Services Quarterly second (13\%) (Table 15, online only).

\section{Benefits of research to practice}

Descriptive statistics were used to assess respondents' perceptions of the benefits of research to practice. Respondents scored 10 possible benefits 
on a 3-part Likert scale ("very important," "somewhat important," and "not important"). With the exception of the benefit "contributes to career advancement," more than $60 \%$ of those responding found every benefit listed "very important." Two benefits - "demonstrates the value of the library and its impact on users to funding authorities" and "provides guidance in evaluating, improving, and initiating new library collections, services, and operations" - were ranked "very important" by almost three-quarters of the respondents (both 74\%) (Table 16, online only).

Significant differences were observed among respondents from different work settings for 3 benefits: three-quarters of hospital librarians found the contribution of research to patient care to be "very important," compared to $60 \%$ of academic librarians. Significantly more academic librarians than hospital librarians said that research was a "very important" contribution to career advancement (53\% versus 36\%); and a significantly higher percentage of academic librarians felt that creating new knowledge to improve the profession was a "very important" reason to conduct research, in comparison to those in hospital settings (76\% versus $65 \%$ ). The results yielded no statistical significant differences in all other perceived benefits between groups.

\section{Research competencies and preferences}

Respondents were asked to describe their skill levels for 9 research skills identified in the 2007 MLA research policy statement [3] on a 3-point Likert scale ("highly skilled," "average," and "very little skill"). One-third of all respondents rated themselves as "highly skilled" in doing collaborative research with a team (32\%) and accurately summarizing research findings for professional communication (30\%). Four skills areas in which respondents reported "very little skill" were knowledge of and ability to use common statistical techniques (61\%), ability to obtain funding and resources for internal and external research projects $(54 \%)$, ability to understand and assess validity of statistical research results (52\%), and ability to select appropriate methodologies for a given research question (42\%). Significant differences were observed between groups for 5 of the skills in the MLA research skills set. Academic librarians reported significantly higher levels of knowledge or abilities than did hospital librarians in the following areas: participating in collaborative research, summarizing research findings, defining research questions, understanding the strengths and limitations of research studies, and assessing the validity of statistical results (Table 17, online only).

\section{Barriers to and supports for conducting research}

Respondents were asked to score the importance of different factors that had limited their research participation. Most reported that a "lack of time allotted to research at work" was a "very important" barrier (65\%). Other issues that ranked high in importance were: "lack of employer support" $(45 \%)$, "lack of time to acquire research skills" (45\%), "lack of training in research design and methods" (43\%), "lack of funding for research training" (43\%), "lack of statistical support" $(41 \%)$, and "lack of funding for research projects" (40\%). Significant differences between groups were found in 6 barrier categories, including the top 3 barriers cited most often, with hospital librarians consistently assigning more importance to each of these than academic librarians (Table 18, online only).

Large majorities of both academic and hospital librarians reported they would welcome opportunities to do research with other experienced researchers (91\% and $74 \%$, respectively) and participate in extra training to acquire research skills if classes were convenient and affordable $(83 \%$ and $81 \%$, respectively). When asked about their training preferences, the top ranked training options were workshops sponsored by local chapters (67\%), inperson workshops $(65 \%)$, web-based courses $(63 \%)$, and webcasts or teleconferences (62\%) (Table 19, online only).

\section{DISCUSSION}

Comparing our study to the 2002 Powell et al. study, which explored a wide range of research activities for library and information sciences (LIS) practitioners including health sciences librarians, we found that a lesser but still considerable number of respondents had read research articles at least once a month (95\% versus 79\%) [15]. Another 2012 study of academic librarians [16] corroborated this high reading level, finding that $78 \%$ of them regularly scanned research-based literature, while 66\% regularly read the full research articles. Likewise, we found that a high percentage of health sciences librarians (58\%) had applied published research to practice, also in accordance with the Powell et al. 
study, which reported that $66 \%$ had "occasionally" or "frequently" applied research findings in the literature to practice [15].

Our findings differed from Powell et al. in that we found fewer respondents (44\%) had conducted their own research compared to Powell et al., who reported $66 \%$ had conducted position-based research and 59\% LIS-type research [15]. Our study was, however, more in line with another UK study, which found that $47 \%$ of UK health librarians had research involvement in the previous 2 years [17]. A high level of research involvement by academic librarians is shown in our study as well as in others (59\% versus $62 \%$ and $66 \%$, respectively) [16, 18$]$. Research grant writing by health sciences librarians may have slightly increased from $29 \%-30 \%$ in the 1990 s to $33 \%[19,20]$, as found in our study. We also noted an increase in grant involvement by academic librarians (from 26\% to 65\%) and, conversely, a decrease by hospital librarians (from $34 \%$ to $22 \%$ ) [20]. In addition, health sciences librarians might participate more often in research grant-writing activities than their LIS counterparts (33\% versus $16 \%$ ) [21]. The distribution of research methods employed by health sciences librarians reported in our study differed from the methods observed by Gore et al. in Bulletin of the Medical Library Association (BMLA)/JMLA articles [11]. While qualitative methods represented fairly similar percentages (18\% and $14 \%$, respectively), far fewer librarians in our study reported using solely quantitative methods ( $24 \%$ versus $88 \%$ ).

Additionally, over half (54\%) self-reported the use of mixed methods research compared to Gore et al. $(9 \%)$ [11].

\section{Subject areas}

Applied topics predominated in all 4 research areas that we examined: applying published research results to practice $(94 \%)$, conducting research $(88 \%)$, applying research to enhance libraries (94\%), and obtaining research grants (80\%). Topical emphases in each of these areas were similar with the exception of research grant topics, which focused on outreach, end-user education, and technology topics, possibly reflecting the funding priorities of the various granting entities. We found that research conducted by librarians had a stronger focus on applied research in comparison to the Gore et al. study (88\% versus $70 \%$ ) and less emphasis on "professional concerns" and "related fields," with no reports of "theoretical" or "general" research [11]. This might reflect that unpublished research was a significant component of our study. Studies that have analyzed practitioner publications and interests have repeatedly mentioned a tendency for them to be action research, local, and largely unpublished through traditional communication channels [22-28].

\section{Institutional affiliation and research productivity}

Librarians with hospital library affiliations who participated in our survey were significantly less likely than those in academic settings to have designed and conducted research, written research grants, presented research findings, or authored research publications. This disparity was also observed in Fenske's analysis of research productivity in different institutional settings (academics, 64\%; hospital librarians, 36\%) [20], in the sources of authorship in the BMLA/JMLA identified in the Gore et al. study (academics, 56\%; hospital librarians, 2\%) [11], and in Harvey's study of abstracts from MLA annual meetings (academics, 70\%; hospital librarians, 15\%) [29].

\section{Research benefits, barriers, and competencies}

As of August 2015, no published studies of health sciences librarians and few studies in the LIS literature addressed perceived research benefits. The studies that did exist $[28,30]$ differed appreciably from the research attitudes of health sciences librarians described in our study, ranking professional development and promotion and tenure requirements as important motivators, whereas both health sciences academic and hospital librarians in our study ranked demonstration of the value and impact of libraries and provision of guidance as primary motivating factors. The top barrier to research for health sciences librarians was lack of time, nearly universally mentioned as the greatest obstacle in other studies [15, 16, 28]. Further, in a related area of scholarship, that of writing for publication, librarians consistently cited a lack of time as the primary reason for low or nonexistent publication productivity [29, 31-33]. Other significant barriers identified in our survey, such as lack of institutional support and training, have also been reported in other studies [15, 20, 28]. While research competencies have received scant 
attention in the LIS literature, a recent case study of Canadian academic librarians reflected similar results to those obtained in our study: analysis of data and selection of an appropriate methodology for research were top ranked learning needs [18].

\section{Limitations}

Due to the voluntary nature of the survey, the findings may not be generalizable to the broader population of health sciences librarians across work settings. Response rates and distributions were similar to prior research, providing some confidence that our findings are comparable. Despite piloting, wording for questions in several instances was ambiguous; for example, response categories for question 2 were not mutually exclusive; instructions were unclear for question 3; and question 22 conflated 2 related but different issues. During analysis, we avoided drawing unwarranted inferences and conclusions based on these data. Finally, although we provided a definition of research to respondents, we observed in the openended responses that some respondents might have had difficulty with the concept of research and differentiating between research done to support library practice and research done to support users and stakeholders. Other studies have noted similar difficulties of differentiation and that librarians frequently have problems understanding the concept of research [15, 34].

Our study indicated that many health sciences librarians regularly read research literature and apply research results to practice. This suggests that for those practicing librarians who have neither the opportunity nor inclination to engage in research, they can still make use of research results in the literature and apply them to affect practice decisions and improve services.

This study also highlights an opportunity for publishers and editors of research literature to actively promote discussions of practice implications by encouraging authors to delineate the practice implications of their results and by providing space for practitioners to report effective and new applications of research results gleaned from the literature in their own practice settings. A lesser number of librarians, but still a relatively high number, reported in our study that they enhanced their libraries based on the research data obtained from their own research. These positive reports of modifying or initiating new services based on research results could encourage more practitioners to seek out additional training, potential research partners, and opportunities to initiate new research projects. In addition, health sciences librarians' attitudes about the benefits of and barriers to research engagement and their research learning needs raise important issues for the profession and MLA. Our findings highlight the need for further investment by employers and other stakeholders in supporting librarian-based research to facilitate information use in libraries and communicate value to and impact on librarians' information consumers and the institutions they serve.

It is encouraging that the results of this study show that health sciences librarians are actively engaged in and care about research. More structured follow-up studies are necessary to investigate the extent to which research is conducted, applied, and published by health sciences librarians, including types of research undertaken, methodologies employed, and subjects studied. The reading habits and influencing behaviors of health sciences librarians also warrant further study, as research results may increasingly be communicated through channels other than peer-reviewed professional journals. Since sufficient studies have been conducted on research barriers, including the data in our study, this knowledgebase could provide a basis for future intervention studies that aim to assess the impact of various factors that shape and affect librarians' research and writing productivity, such as work affiliation, institutional support, collaborative opportunities, and training. Future studies are needed to confirm and extend the present findings and advance the creation, integration, and communication of health information research.

\section{AUTHORS' CONTRIBUTIONS}

Susan Lessick, Carol Perryman, Brooke L. Billman, and Sandra L. De Groote were involved in the conception and design of the survey. De Groote was involved in the institutional review board submission. All authors were involved in the analysis and interpretation of data. Billman was involved with data curation and visualization. All authors were involved in drafting the manuscript. Lessick, Perryman, Billman, and Kristine M. Alpi were involved in revising the manuscript critically. All authors gave final approval of the version to be 
published and agreed to be accountable for all aspects of the work.

\section{ACKNOWLEDGMENTS}

The authors acknowledge with appreciation the members of the MLA Research Section Strategic Planning Committee for their exchange of ideas and critical review of the survey. The authors also convey thanks to the MLA Research Section for funding access to the online survey platform, SurveyMonkey.

\section{REFERENCES}

1. Medical Library Association. Shaping the future: the strategic plan of the Medical Library Association. MLA News. 1987 Apr;194(suppl):S1-S16.

2. Medical Library Association. Using scientific evidence to improve information practice: the research policy statement of the Medical Library Association. Chicago,

IL: The Association; 1995.

3. Medical Library Association. The research imperative: the research policy statement of the Medical Library Association [Internet]. Chicago, IL: The Association; 2007 [cited 30 Oct 2015]. <http://www.mlanet.org/p/cm/ld/ fid $=541>$.

4. Marshall JG. Linking research to practice: the rise of evidence-based health sciences librarianship. J Med Libr Assoc. 2014 Jan;102(1):14-21. DOI: http://dx.doi.org/10. 3163/1536-5050.102.1.005.

5. Davidoff F, Florance V. The informationist: a new health profession. Ann Intern Med. 2000 Jun;132(12):9968. DOI: http://dx.doi.org/10.7326/0003-4819-132-12200006200-00012.

6. Cooper ID. Is the informationist a new role? a logic model analysis. J Med Libr Assoc. 2011 Jul;99(3):189-92. DOI: http://dx.doi.org/10.3163/1536-5050.99.3.004.

7. Eldredge JD, Ascher MT, Holmes HN, Harris MR. The new Medical Library Association research agenda: final results from a three-phase delphi study. J Med Libr Assoc. 2012 Jul;100(3):214-8. DOI: http://dx.doi.org/10.3163/ 1536-5050.100.3.012.

8. Medical Library Association, Research Section, Strategic Planning Committee. Strategic plan 2012-2016. Chicago, IL: The Association; 2011 Nov.

9. Glaser BG, Strauss AL. The discovery of grounded theory: strategies for qualitative research. Chicago, IL: Aldine Publishing; 1967.

10. Dimitroff A. Research in health sciences library and information science: a quantitative analysis. Bull Med Libr Assoc. 1992 Oct;80(4):340-6.

11. Gore SA, Nordberg JM, Palmer LA, Piorun ME.

Trends in health sciences library and information science research: an analysis of research publications in the Bulletin of the Medical Library Association and Journal of the Medical Library Association from 1991 to 2007. J Med Libr Assoc. 2009 Jul;97(3):203-11. DOI: http://dx.doi.org/ 10.3163/1536-5050.97.3.009.

12. Lessick S. Personal communication with Tomi Gunn (Manager of Membership Services, Medical Library Association). 6 May 2011.

13. Medical Library Association. MLA 2007 membership survey: results overview [Internet]. Chicago, IL: The Association; 2007 [cited 28 Dec 2015]. <http://www. mlanet.org $/ \mathrm{p} / \mathrm{do} / \mathrm{sd} / \mathrm{sid}=936 \&$ fid=1773\&req=direct $>$. 14. Medical Library Association. MLA compensation \& benefits survey. Chicago, IL: The Association; 2013. 15. Powell RR, Baker LM, Mika JJ. Library and information science practitioners and research. Libr Inf Sci Res. 2002;24(1):49-72. DOI: http://dx.doi.org/10.1016/ S0740-8188(01)00104-9.

16. Kennedy MR, Brancolini KR. Academic librarian research: a survey of attitudes, involvement, and perceived capabilities. Coll Res Libr. 2012 Sep;73(5):43148. DOI: http://dx.doi.org/10.5860/crl-276.

17. McNicol S. Practitioner research in libraries: a crosssectoral comparison. Libr Inf Res. 2004 Spring;28(88):3441.

18. Schrader AM, Shiri A, Williamson V. Assessment of the research learning needs of University of

Saskatchewan librarians: a case study. Coll Res Libr. 2012 Mar;73(2):147-63. DOI: http://dx.doi.org/10.5860/crl-235. 19. Burdick A, Doms CA, Doty CC, Kinzie LA. Research activities among health sciences librarians: a survey. Bull Med Libr Assoc. 1990 Oct;78(4):400-2.

20. Fenske RE, Dalrymple PW. Factors influencing research productivity among health sciences librarians. Bull Med Libr Assoc. 1992 Oct;80(4):353-60.

21. Luo L. Fusing research into practice: the role of research methods education. Libr Info Sci Res. 2011 Jul; 33(3):191-201. DOI: http://dx.doi.org/10.1016/j.lisr.2010. 12.001.

22. Haddow G, Klobas JE. Communication of research to practice in library and information science: closing the gap. Libr Inf Sci Res. 2004 Winter;26(1):29-43. DOI: http:// dx.doi.org/10.1016/j.lisr.2003.11.010.

23. McClure CR. Increasing the usefulness of research for library managers: propositions, issues, and strategies. Libr Trends. 1989 Fall;38(2):280-94.

24. McClure CR, Bishop A. The status of research in library/information science: guarded optimism. Coll Res Libr. 1989 Mar;50:127-43.

25. Blick AR. Information science research versus the practitioner. In: Dietschmann HJ, ed. Representation and exchange of knowledge as a basis of information processes. Amsterdam, The Netherlands: North Holland; 1984. p. 231-44. Cited in: Haddow G. Communicating research to practice: the role of 
professional association publications. Libr Inf Res. 2011; 34(108):33-44.

26. Wilson V. Formalized curiosity: reflecting on the librarian practitioner-researcher. Evid Based Libr Inf Pract. 2013 8(1):111-7.

27. Schlogl C, Stock WG. Practitioners and academics as authors and readers: the case of LIS journals. J

Documentation. 2008;64(5):643-66. DOI: http://dx.doi. org/10.1108/00220410810899691.

28. Fox D. The scholarship of Canadian research university librarians. Partnership: Can J Inf Pract Res. 2007;2(2):1-25.

29. Harvey SA, Wandersee JR. Publication rate of abstracts of papers and posters presented at Medical Library Association annual meetings. J Med Libr Assoc. 2010 Jul;98(3):250-5. DOI: http://dx.doi.org/10.3163/15365050.98.3.014.

30. Berg SA, Jacobs HLM, Cornwall D. Academic librarians and research: a study of Canadian library administrator perspectives. Coll Res Libr. 2013 Nov;74(6): 560-72. DOI: http://dx.doi.org/10.5860/crl12-366.

31. Bradley F. Writing for the profession: the experience of new professionals. Libr Manag. 2008;29(8/9):729-45. DOI: http://dx.doi.org/10.1108/01435120810917332.

32. Schlackman E. An exploration of the motivations and barriers for UK academic librarians to conduct research [master's dissertation]. Bristol, UK: University of the West of England; 2009.

33. Clapton J. Library and information science practitioners writing for publication: motivations, barriers and supports. Libr Inf Res. 2010; 34(106):7-21. 34. Weaver SM. The professional reading habits of American librarians. Paper presented at: Libraries for life: democracy, diversity, delivery. 68th International Federation of Library Associations and Institutions Council and General Conference; 18-24 Aug 2002; Glasgow, Scotland [cited 24 Dec 2015]. <http://archive. ifla.org/IV/ifla68/papers/166-118e.pdf $>$.

\section{AUTHORS' AFFILIATIONS}

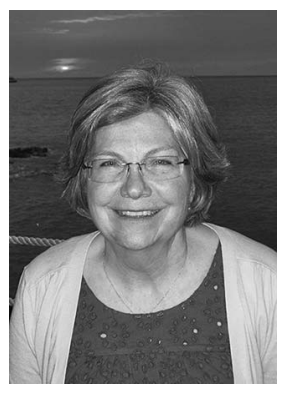

Susan Lessick, MA, MLS, AHIP, FMLA, slessick@ uci.edu, Distinguished Librarian and Librarian Emeritus, University of California, Irvine, 7468 East Calle Durango, Anaheim, CA 92808; Carol Perryman, PhD, Cp1757@ gmail.com, Assistant Professor, School of Library and Information Science, Texas Woman's University, P.O. Box 425438, Stoddard Hall, Room 404, Denton, TX 76204-5438; Brooke L. Billman, MA, AHIP, brooke.billman@ahsl.arizona.edu, AZHIN and Special Projects Librarian, Arizona Health Sciences Library, University of Arizona, 1505 North Campbell Avenue, Tucson, AZ 85724-5079; Kristine M. Alpi, MLS, MPH, AHIP, kristine_alpi@ncsu.edu, Director, William Rand Kenan, Jr. Library of Veterinary Medicine, NCSU Libraries, and Adjunct Assistant Professor, Department of Population Health \& Pathobiology, College of Veterinary Medicine, North Carolina State University, 1060 William Moore Drive, Raleigh, NC 27607; Sandra L. De Groote, MLIS, AHIP, sgroote@uic.edu, Scholarly Communications Librarian and Associate Professor, University Library, University of Illinois at Chicago, 801 South Morgan Street M/C 234, Chicago, IL 60607; Ted D. Babin Jr., mtbabin@ mail.twu.edu, Texas Woman's University, P.O. Box 425438, Denton, TX 76204-5438

Received December 2015; accepted December 2015 